\title{
How Do Estimates of Inflation Persistence in Malta Compare with Other EU Countries?
}

\author{
Brian Micallef ${ }^{1} \&$ Reuben Ellul ${ }^{2}$ \\ ${ }^{1}$ Manager, Research Department, Central Bank of Malta, Malta \\ ${ }^{2}$ Principal Economist, Economic Analysis Department, Central Bank of Malta, Malta \\ Correspondence: Brian Micallef, Manager, Research Department, Central Bank of Malta, Castille Place, Valletta, \\ VLT1060, Malta. E-mail: micallefb@ centralbankmalta.org
}

Received: May 8, 2020

Accepted: June 3, 2020

Online Published: June 8, 2020

doi:10.5539/ijef.v12n7p31

URL: https://doi.org/10.5539/ijef.v12n7p31

\begin{abstract}
After the European sovereign debt crisis in 2012, inflation has been unexpectedly low across most of the economies making up the euro area, as well as the Monetary Union aggregate, with economists referring to this phenomenon as the "missing inflation" puzzle. As the smallest and one of the most open economies in the euro area, Malta has also registered a period of low inflation post-2012, despite registering an average GDP growth rate of 6.9\% per annum over the period 2013-2019. This paper estimates the extent of inflation persistence of Malta and a number of EU economies for both the pre- and post-2012 period. Measures of persistence are computed as the sum of autoregressive coefficients derived from univariate regressions on both aggregated and disaggregated inflation series. Estimates of persistence in Malta have increased when the sample covers the post-2012 period. In terms of the main sub-components, energy inflation has a substantially higher persistence compared to the pre-2012 period, reflecting both external and country-specific factors. Most other EU countries also reported an increase in persistence when including the post-2012 period in the sample although the estimates for Malta, both at the aggregate and disaggregated indices, remain less persistent.
\end{abstract}

Keywords: inflation persistence, aggregation effect, Malta

\section{Introduction}

After the European sovereign debt crisis in 2012, inflation has been unexpectedly low across most of the euro area and its constituent economies. A number of economists have referred to this phenomenon as the "missing inflation" puzzle, reflecting the unmet expectations of higher inflation given the recovery in economic activity (Ciccarelli \& Osbat, 2017). This "missing inflation" has affected all economies, both those that were impacted severely by the European sovereign debt crisis as well as those that emerged unscathed.

As one of the most open and smallest economies in the euro area, Malta has also experienced relatively low inflation after 2012. This low inflation occurred despite the country having one of the fastest growing economies in the EU, with real GDP growth averaging 6.9\% during the period 2013-2019, and the unemployment rate falling to its historical lows (Grech et al., 2018). Chart 1 plots the inflation rate in Malta between 1997 and 2019, being the year-on-year growth rate measured by the Harmonised Index of Consumer Prices (HICP). Until 2012, inflation in Malta tended to fluctuate around a remarkably stable mean of around 2.7\%. Since 2013, however, inflation has remained persistently lower than its long-run average, having reverted back to this average only once for a brief period of time in the second half of 2018. This relatively low inflation period has reduced the long-term average from $2.7 \%$ for the period 1997-2012 to $2.3 \%$ in the full sample period ending 2019. This suggests changes in the persistence of inflation, which is defined as the tendency of inflation to gradually return to its long-term mean following a shock (Altissimo et al., 2006).

A proper understanding of the determinants and patterns of inflation persistence is important for analysts and policy makers for at least three reasons. First, keeping prices stable in the euro area is the primary objective of the European Central Bank (ECB) and thus developments in the underlying patterns of inflation have important significance for a suitable conduct of monetary policy. Indeed, the degree to which a shock's effects on inflation are persistent will have important implications for the monetary policy response. Second, inflation differentials could arise due to different degrees of country-specific inflation persistence with respect to the rest of the euro 
area. In a monetary union, this could adversely affect a country's external price competitiveness. Finally, a better understanding of inflation mechanisms and the inflation parameter stability is necessary for the development of econometric and structural models that are regularly used for policy analysis and forecasting in both academia and policy institutions.

This paper uses a measure of inflation persistence that is computed as the sum of autoregressive coefficients based on univariate regressions. These persistence estimates are computed both the overall HICP inflation and its main sub-components for Malta and a number of EU economies. In addition to the euro area as a whole, the latter include both small and open economies, and larger economies such as Italy and the UK due to their close trading links with Malta. It thus seeks to address the following research questions: (i) How persistent is the overall inflation process in Malta? (ii) Has it changed over time? (iii) Which sub-components are the most persistent and have they remained stable over time? (iv) Has persistence in Malta followed the same pattern as in other EU economies?

The rest of this article is structured as follows. Section 2 reviews the main findings from the literature. Sections 3 and 4 discuss the methodology and data used to obtain the estimates of inflation persistence, respectively. Estimates of persistence for the overall HICP inflation and the main sub-components are computed for Malta and a number of economies in the EU, the results of which are discussed in Sections 5 and 6, respectively. In Section 7 we discuss the overall findings and compare the results for Malta with those of the other economies. Section 8 concludes and provides avenues for further research.

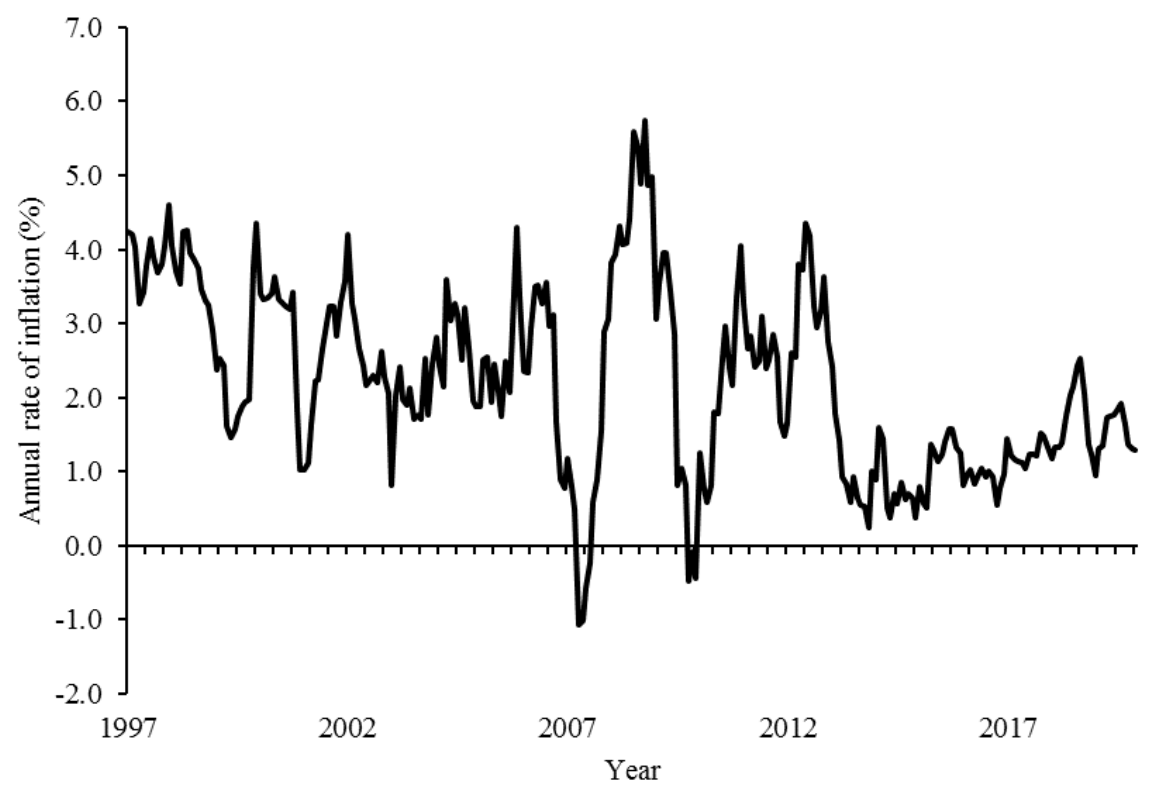

Figure 1. HICP inflation in Malta (1997-2019), year-on-year percentage change (\%)

Sources: Eurostat, authors' calculations.

\section{Literature Review}

Models of inflation with micro-foundations tend to be based on a series of stylised facts and assumptions on the pricing behaviour of firms, following Taylor (1980) and Calvo (1983). The path of inflation dynamics and price adjustment speed, however, will depend on price setting behaviour types of individual agents. The leading framework in the literature to model price inflation is the New Keynesian Phillips Curve (NKPC). The baseline microfounded version of this framework, however, where inflation depends only on forward looking expectations and the output gap was unable to reproduce the high inflation persistence found in the data (Fuhrer \& Moore, 1995). As a result, a number of different mechanisms were suggested to explain and include inflation persistence into the structure of this framework. Price persistence is built in contracting models with workers considering real wages levels relative to previous and succeeding cohorts of workers, following Buiter and Jewitt (1981) and Fuhrer and Moore (1995). A backward-looking rule-of-thumb is allowed for in Gali and Gertler (1999), which by design introduces a backward-looking element to aggregate inflation dynamics. Christiano et al. 
(2005) introduce nominal rigidities in firms using a mechanism introduced by Calvo (1983). These are unable to re-optimise prices and will then, partly or completely, adjust their prices based on past average inflation rates. Benati (2008), however, suggests that the inclusion of backward-looking elements might be misleading, as in stable monetary regimes with clearly defined nominal anchors, inflation acts as a forward-looking phenomenon. Generally, the conduct of monetary policy by monetary authorities, and its credibility is seen to have an important influence on inflation persistence (Fuhrer, 2010; Bratsiotis et al., 2015). A number of studies have also looked at how government may affect inflation persistence through labour market structural reforms (Geronikolau et al., 2016; d'Agostino et al., 2018).

The modelling choices behind the pricing behaviour of agents will have a number of implications on the sources and effects of inflation persistence. In the NKPC that is nowadays the backbone of most structural models used in academia and policy institutions, there are three identifiable inflation persistence sources. The first, referred to as intrinsic persistence arises from inertia, that is, the backward-looking component in price formation. The second, known as expectations-based persistence, refers to the manner with which expectations about future inflation are formed by economic agents. The final source is extrinsic persistence and this arises from persistent fluctuations in the determinants of inflation, like real marginal costs, which is affected by firms' cost structure.

A number of studies have analysed the different sources of inflation persistence discussed above for various economies (Alogoskoufis \& Smith, 1991; Cogley \& Sargent, 2005; Dossche \& Everaert, 2005; Pivetta \& Reis, 2007; Cogley \& Sbordone, 2008; Cogley et al., 2010; Misztal, 2017; Bems et al., 2018). Empirical studies analysed a number of data sources, such as aggregate consumer and macroeconomic price series in the euro area as well as member countries, and a number of micro-level producer and consumer prices and firm-level surveys. Benati (2004) and Levin \& Piger (2004) carry out a wide-ranging survey of the literature. Altissimo et al. (2006) find that under the current monetary policy regime, the degree of inflation persistence estimated for the euro area is moderate but that retail prices in the United States appear to be less sticky than in the euro area. Moreover, significant sectoral heterogeneity is found in persistence estimates, while price decreases appear not to be uncommon.

There remains a considerable degree of uncertainty around persistence estimates, partly due to various methodological approaches used to measure it and the sensitivity in the choices of price indices and sample period studied.

Univariate time series approaches are used in most empirical studies to estimate intrinsic inflation persistence. These tend to be autoregressive processes, with estimates of inflation persistence measured as the sum of autoregressive coefficients from univariate regressions (Levin \& Piger, 2004; O'Reilly \& Whelan, 2004; Gadzinski \& Orlandi, 2004; Lünnemann \& Mathä, 2004). The literature finds that a high proportion of measured inflation persistence estimates relates to breaks in the mean of inflation processes. For example, when applying univariate regressions to a historic time-series, which may begin in the 1970s or 1980s, studies report very persistent inflation processes in both the United States and countries within the euro area. On the other hand, if structural breaks in mean inflation are accounted for, studies find more moderate inflation persistence estimates (Lünnemann \& Mathä, 2004).

A further finding in the literature is a strong heterogeneity in persistence estimates between sectors and countries. Generally, energy and unprocessed food are found to have a low degree of inflation persistence, reflecting seasonality and the fluctuations in food and international energy prices. On the contrary, prices in services and non-energy industrial goods tend to be more persistent. These differences may reflect diverse price-setting processes, which may, in turn, be determined by the market structures. For instance, administered prices tend to be more persistent than those prices that are market determined. Some studies also look into aggregation effects, this occurs where persistence estimates in aggregated or overall price indices is different from estimates of the disaggregated series. This may be attributable to idiosyncratic shocks in disaggregate sub-indices cancelling or offsetting effects between them, as well as the possibility that a larger weight may be given to more persistent series (Altissimo et al., 2006).

Inflation persistence estimates in Malta are rather scarce. A first-order autoregressive model to sectoral Retail Price Index (RPI) sub-indices was applied in Demarco (2004) to estimate a measure of core inflation for Malta. This study reported low persistence in the food and energy sub-indices, while certain sub-indices in industrial goods and services had a modest degree of persistence. The categories showing persistence were personal care, recreation and culture, housing, household equipment and maintenance, and other goods and services. Two other studies look at aggregate inflation persistence in the euro area as well as in newer EU countries (Franta et al., 2010; Vladova \& Pachedijiev, 2008). Both studies find that the Maltese economy has lower persistence estimates, 
and that estimates for Malta are generally similar to those of other euro area countries, albeit lower than estimates for most of the eastern EU countries.

\section{Methodology}

Following Lünnemann and Mathä (2004), persistence is measured as the sum of auto-regressive coefficients from a univariate regression model. The below specification was estimated for the overall HICP index and various sub-indices:

$$
\pi_{i, t}=c_{i, t}+\sum_{k=1}^{K^{*}} \beta_{i, k} \pi_{i, t-k}+\varepsilon_{i, t} \quad \text { with } \rho_{i}=\sum_{k=1}^{K^{*}} \beta_{i, k}
$$

where $\pi_{i, t}$ refers to the average year-on-year inflation rate in quarter $t$ for index $i$, while the persistence parameter, $\rho_{\mathrm{i}}$, refers to the sum of autoregressive coefficients. $\mathrm{K}^{*}$ stands for the optimal lag length identified by the Akaike information criterion. The optimal lag length was identified for each individual regression, while every equation included a constant term, $c_{i, t}$.

A process will have mean-reversion - that is, will tend to revert to a long-term or constant mean - when the autoregressive coefficient $\rho$ falls within the range $0<\left|\rho_{i}\right|<1$. A positive autoregressive coefficient means that the process will revert back to its long-term mean in a smooth manner. Negative coefficients imply that the series will converge to their means following oscillatory patterns. On the other hand, if $\left|\rho_{i}\right|=1$, the series contains a unit root process, meaning that the process will not revert back to its mean following a shock. The length of time needed for mean reversion to occur after a shock is also based on the autoregressive coefficient. Lower $\rho$ values are associated with a quicker mean reversion, and vice versa. A common way to measure the speed with which a process reverses to its mean is the calculation of the shock's half-life. This will indicate the number of reference periods where the shock's effects are larger than half of the initial impact. The half-life measured in years is calculated as $\frac{\ln (0.5)}{\ln \left(\left|\rho_{i}\right|\right)}$.

\section{Data}

Estimates of inflation persistence using the above method are based on HICP indices, at different levels of aggregation, as published by Eurostat, starting from January 1996 until December 2019. This analysis refers to annual inflation rates, reported at a quarterly (that is, three-month) frequency. Persistence parameters were estimated for overall HICP inflation, intermediate, and lower levels of statistical aggregation. Intermediate levels of disaggregation relate to five sub-index components, namely unprocessed food, processed food, non-energy industrial goods, energy, and services. In addition, the services sub-index is further disaggregated in five components: communication, housing, recreation, transport and miscellaneous. The high level of disaggregation include 12 sub-indices: food and non-alcoholic beverages (CP01); alcoholic beverages, tobacco and narcotics (CP02); clothing and footwear (CP03); housing, water, electricity, gas and other fuels (CP04); furnishings, household equipment and other routine maintenance (CP05); health (CP06); transport (CP07); communications (CP08); recreation and culture (CP09); education (CP10); restaurants and hotels (CP11); miscellaneous goods and services (CP12).

The estimates are conducted for Malta, the overall euro area as well as a set of open and small economies which share characteristics similar to the Maltese economy, or who have significant trade links with Malta. Small open economies included in the study are Cyprus, Estonia, Ireland, Luxembourg and Slovenia. These are among the most open economies in the euro area, with imports of goods and services exceeding $70.0 \%$ of GDP in all cases. The results are also computed for Italy and the United Kingdom (UK). The latter two were chosen since they are two of Malta's largest trading partners due to geographical proximity (Italy) and historical colonial ties (UK).

All the univariate regressions are estimated over two periods. The first covers the period 1997-2012 and is intended to capture the degree of persistence preceding the 'low inflation' period that took place in the aftermath of the European sovereign debt crisis. The second periods refer to the full sample (1997-2019).

As caveats, it is important to highlight two facts. Data quality tends to break down in disaggregated series. These series may have significant structural breaks, including changes in the indices' composition or in the method with which data is collected. Moreover, one-off episodes will have stronger effects on disaggregated series. Secondly, indices' statistical weights may have been updated, and changed strongly over time. Hence, whereas specific disaggregated series may show comparatively high persistence estimates, at a more aggregated level these could be lower, reflecting offsetting developments in the separate sub-indices over the years. When the degree of persistence implied at a disaggregate level is different from that found in the component at a higher 
level of statistical aggregation, it is termed an aggregation effect. These effects may also appear across time, with the weights of different components varying over the years.

\section{Results for Malta}

Table 1 shows autoregressive coefficients estimates for Malta at different aggregation levels over two time periods. For the full-sample, the persistence parameter estimate for overall, or headline, HICP inflation in Malta is 0.66 . This is a significant increase compared to the previous estimate of 0.27 which covered the pre-2012 period. The half-life associated with the full-sample parameter has increased to 20 months, up from 6 months for the pre-2012 period.

Inflation persistence in Malta in the pre-2012 period was substantially lower than those reported in the literature for other euro area countries. However, a closer inspection at the disaggregated sub-indices point towards the presence of bias caused by aggregation effects, with many HICP sub-components yielding higher persistence estimates than that observed in overall HICP.

In the pre-2012 period, the services and non-energy industrial goods sector components exhibited higher inflation persistence than energy and unprocessed food. This finding is similar to other results reported in the literature. On the contrary, the prices for energy and unprocessed food tend to change more often in response to frequent fluctuations in input prices. For instance, the low persistence of the energy index tends to be associated with the fluctuations in the international oil prices while that in the unprocessed food category is due to the pronounced seasonal pattern of some of the indices in this category (Note 1).

The services index exhibits the highest degree of persistence compared with the other HICP categories. In addition, all five sub-components of the services index have persistence parameters which exceed 0.60 . The higher reliance on labour input and therefore wage costs may explain the higher persistence estimates for services. Wages are changed rather infrequently, or at irregular intervals. Moreover, they do not tend to be volatile. Inflation persistence would therefore be expected to be higher where the labour content is higher. Price regulations in various service categories may also explain why some indices do not respond quickly to supply and demand conditions (Note 2). Persistence estimates for non-energy industrial goods and processed food in Malta are slightly less than 0.60 .

At further disaggregation levels, where one-off events or sector-specific developments become more pronounced, there is more heterogeneity. At the 12-level classification, an increase in inflation persistence is observed, with all sub-indices reporting persistence parameters higher than 0.50 . The highest persistence is recorded in Communications (CP08), Health (CP06) and Alcoholic beverages, tobacco and narcotics (CP02). One can expect that sub-indices including prices for items with strong government policy influence (e.g. tobacco and spirits) will exhibit a higher degree of persistence.

The second column in Table 1 plots the estimates for the full sample. The increase in overall persistence implies a lower degree of aggregation bias. In other words, the extent of the aggregation bias, that is, the fact that the disaggregated sub-components of the HICP have a higher estimate of persistence than the overall HICP, has significantly diminished.

The estimates for the five main sub-components of HICP remain broadly unchanged with the exception of energy. The latter registered a sharp increase, rising from 0.39 in the pre-2012 period to 0.73 in the full sample. This increase in the persistence of energy prices reflects not only the decrease in oil prices in euro terms, but also the impact of the energy reforms introduced since 2013, including the reduction in electricity tariffs (Grech, 2014) and hedging agreements aimed at providing stability in energy prices. Indeed, the average annual growth rate in the energy sub-component of the HICP index, estimated at $-1.99 \%$ over the period 2013-2019, is substantially lower than its long-term average of $4.43 \%$. Reflecting these dynamics, energy price inflation since 2013 has never reached its long-term average, which explains the rise in inflation persistence during this period. 
Table 1. Estimates of inflation persistence in Malta

\begin{tabular}{lcc}
\hline & & Period \\
HICP component & $1997-2012$ & $1997-2019$ \\
\hline Overall HICP & 0.28 & 0.66 \\
Food \& non-alcoholic beverages & 0.69 & 0.70 \\
Alcoholic beverages, tobacco \& narcotics & 0.79 & 0.81 \\
Clothing \& footwear & 0.58 & 0.41 \\
Housing, water, electricity, gas \& other fuels & 0.69 & 0.76 \\
Furnishings, household equip. \& routine maintenance & 0.49 & 0.71 \\
Health & 0.78 & 0.86 \\
Transport & 0.53 & 0.65 \\
Communications & 0.86 & 0.85 \\
Recreation \& culture & 0.74 & 0.70 \\
Education & 0.74 & 0.83 \\
Restaurants \& hotels & 0.51 & 0.51 \\
Miscellaneous goods \& services & 0.52 & 0.61 \\
Energy & 0.39 & 0.73 \\
Unprocessed food & 0.47 & 0.52 \\
Processed food & 0.59 & 0.68 \\
Industrial goods excluding energy (NEIG) & 0.59 & 0.58 \\
Services & 0.72 & 0.74 \\
Services - Communication & 0.86 & 0.86 \\
Services - Housing & 0.62 & 0.61 \\
Services - Recreation & 0.68 & 0.66 \\
Services - Transport & 0.64 & 0.70 \\
Services - Miscellaneous & 0.67 & 0.76 \\
\hline
\end{tabular}

Source. Authors' calculations.

\section{Results for Euro Area and Selected EU Countries}

Table 2 shows the results for the five small and open economies in the euro area: Luxembourg, Cyprus, Estonia, Slovenia and Ireland. For comparison purposes, Table 3 shows the results for the euro area as a whole, as well as the UK and Italy.

Most of the small open economies considered exhibited a relatively high degree of inflation persistence even in the pre-2012 period, ranging between 0.71 in Luxembourg to 0.91 in Ireland and Slovenia. The only exception is Cyprus, with an estimated persistence for the overall HICP of 0.17 in the pre-2012 period. The aggregation bias in Cyprus for the latter period is also quite high and comparable to that observed in Malta, as the persistence parameter of the overall HICP inflation is much lower than for its sub-components.

The pattern in the persistence of the five main sub-components in the pre-2012 period is broadly in line with findings from the literature. Energy and, to a lesser extent, unprocessed food have the lowest degree of inflation persistence compared to services, non-energy industrial goods and processed food. Some indices are also affected by aggregation bias. For instance, the persistence in the overall services index in Luxembourg for the pre-2012 period was lower than for the individual services sub-indices, which range from 0.58 to 0.82 .

The situation in larger economies also exhibits a high degree of heterogeneity with persistence estimates for overall HICP inflation ranging from 0.59 in Italy to 0.91 in the UK for the pre-2012 period. In the euro area and Italy, services and processed food inflation registered the highest persistence although in the UK, services inflation exhibited a relatively low persistence estimate. In the latter case, however, a substantial degree of aggregation bias is found since the individual sub-components have a higher degree of persistence than the overall services index.

All the economies, with the exception of the UK, reported an increase in the overall HICP inflation persistence over the full sample compared with the pre-2012 period. For the small open economy countries, Cyprus by far reported the highest increase in persistence for overall HICP inflation, which rose from 0.17 to 0.81 . Contrary to the case in Malta, however, it is not straightforward to identify the source of this increase in persistence since the individual components moved in opposite direction. Persistence in Cyprus increased substantially in energy and, 
to a lesser extent in services and processed food, but declined in the unprocessed food and industrial goods categories. The increases in persistence reported in the other small open countries were much more modest although all of them exhibit persistence estimates above 0.75, ranging from 0.78 in Luxembourg to 0.94 in Slovenia. The larger economies have also witnessed a convergence in their persistence estimates, which for the full sample range between 0.84 and 0.86 . The slight decline in persistence in the overall HICP inflation in the UK, from 0.91 to 0.87 , occurred from a high level. And even in this case, aggregation bias is present since services and, to a lesser extent, energy and unprocessed food reported an increase in the persistence parameter while the persistence of processed food and industrial goods remained unchanged.

In terms of the individual components, with few exceptions, all countries reported an increase in the persistence estimates for energy inflation, processed food and services. In all cases, the estimated persistence parameters for these components have converged significantly, irrespective of the size and openness of the countries. For energy inflation, persistence estimates for the full sample now range between 0.70 and 0.79 . For processed food and services, the range stands between 0.75 and 0.90 , and 0.84 and 0.94 , respectively.

Table 2. Estimates of inflation persistence in small open economies in the Euro area

\begin{tabular}{|c|c|c|c|c|c|c|c|c|c|c|}
\hline & \multicolumn{2}{|c|}{ Luxembourg } & \multicolumn{2}{|c|}{ Cyprus } & \multicolumn{2}{|c|}{ Estonia $^{1}$} & \multicolumn{2}{|c|}{ Slovenia $^{2}$} & \multicolumn{2}{|c|}{ Ireland } \\
\hline & $\begin{array}{l}1997- \\
2012 \\
\end{array}$ & $\begin{array}{c}1997- \\
2019 \\
\end{array}$ & $\begin{array}{c}1997- \\
2012 \\
\end{array}$ & $\begin{array}{l}1997- \\
2019 \\
\end{array}$ & $\begin{array}{l}1997- \\
2012 \\
\end{array}$ & $\begin{array}{r}1997- \\
2019 \\
\end{array}$ & $\begin{array}{c}1997- \\
2012 \\
\end{array}$ & $\begin{array}{l}1997- \\
2019 \\
\end{array}$ & $\begin{array}{c}1997- \\
2012 \\
\end{array}$ & $\begin{array}{l}1997- \\
2019 \\
\end{array}$ \\
\hline Overall HICP & 0.71 & 0.78 & 0.17 & 0.81 & 0.73 & 0.80 & 0.91 & 0.94 & 0.91 & 0.93 \\
\hline Food \& non-alcoholic beverages & 0.77 & 0.74 & 0.38 & 0.53 & 0.69 & 0.71 & 0.81 & 0.83 & 0.85 & 0.88 \\
\hline $\begin{array}{l}\text { Alcoholic beverages, tobacco \& } \\
\text { narcotics }\end{array}$ & 0.77 & 0.84 & 0.78 & 0.81 & 0.75 & 0.76 & 0.78 & 0.85 & 0.78 & 0.79 \\
\hline Clothing \& footwear & 0.71 & 0.54 & 0.49 & 0.44 & 0.89 & 0.87 & 0.82 & 0.83 & 0.82 & 0.83 \\
\hline $\begin{array}{l}\text { Housing, water, electricity, gas \& other } \\
\text { fuels }\end{array}$ & 0.53 & 0.70 & 0.35 & 0.74 & 0.78 & 0.84 & 0.74 & 0.83 & 0.85 & 0.82 \\
\hline $\begin{array}{l}\text { Furnishings, household equip. \& } \\
\text { routine maintenance }\end{array}$ & 0.54 & 0.67 & 0.24 & 0.65 & 0.84 & 0.82 & 0.85 & 0.94 & 0.97 & 0.95 \\
\hline Health & 0.81 & 0.74 & 0.68 & 0.86 & 0.76 & 0.80 & 0.90 & 0.92 & 0.88 & 0.95 \\
\hline Transport & 0.66 & 0.71 & 0.61 & 0.66 & 0.72 & 0.79 & 0.89 & 0.90 & 0.44 & 0.74 \\
\hline Communications & 0.71 & 0.74 & 0.86 & 0.87 & 0.85 & 0.87 & 0.85 & 0.85 & 0.81 & 0.81 \\
\hline Recreation \& culture & 0.67 & 0.67 & 0.58 & 0.67 & 0.75 & 0.76 & 0.87 & 0.88 & 0.95 & 0.94 \\
\hline Education & 0.73 & 0.61 & 0.63 & 0.94 & 0.91 & 0.91 & 0.90 & 0.91 & 0.42 & 0.63 \\
\hline Restaurants \& hotels & 0.86 & 0.80 & 0.79 & 0.84 & 0.85 & 0.83 & 0.78 & 0.91 & 0.95 & 0.94 \\
\hline Miscellaneous goods \& services & 0.75 & 0.76 & 0.76 & 0.90 & 0.75 & 0.76 & 0.90 & 0.94 & 0.81 & 0.91 \\
\hline Energy & 0.53 & 0.73 & 0.40 & 0.72 & 0.31 & 0.75 & 0.48 & 0.75 & 0.54 & 0.70 \\
\hline Unprocessed food & 0.78 & 0.60 & 0.18 & -0.06 & 0.57 & 0.52 & 0.47 & 0.49 & 0.76 & 0.79 \\
\hline Processed food & 0.81 & 0.86 & 0.69 & 0.86 & 0.73 & 0.75 & 0.85 & 0.90 & 0.85 & 0.89 \\
\hline Industrial goods excluding energy (NEIG) & 0.48 & 0.58 & 0.72 & 0.63 & 0.80 & 0.80 & 0.88 & 0.85 & 0.91 & 0.90 \\
\hline Services & 0.55 & 0.82 & 0.67 & 0.86 & 0.80 & 0.84 & 0.86 & 0.86 & 0.96 & 0.92 \\
\hline Services - Communication & 0.71 & 0.75 & 0.86 & 0.87 & 0.85 & 0.87 & 0.80 & 0.77 & 0.81 & 0.80 \\
\hline Services - Housing & 0.58 & 0.87 & 0.77 & 0.92 & 0.90 & 0.85 & 0.89 & 0.84 & 0.90 & 0.90 \\
\hline Services - Recreation & 0.81 & 0.77 & 0.79 & 0.86 & 0.75 & 0.74 & 0.90 & 0.90 & 0.97 & 0.95 \\
\hline Services - Transport & 0.82 & 0.83 & 0.76 & 0.71 & 0.81 & 0.84 & 0.92 & 0.88 & 0.70 & 0.64 \\
\hline Services - Miscellaneous & 0.75 & 0.67 & 0.68 & 0.94 & 0.71 & 0.83 & 0.82 & 0.84 & 0.66 & 0.89 \\
\hline
\end{tabular}

Note. ${ }^{1}$ For Estonia, the indices for NEIG, overall services, housing services, miscellaneous services and services related to recreation are only available from December 1997. Data for energy and transport services are available from December 2000.

${ }^{2}$ For Slovenia, the indices for energy, unprocessed and processed food, NEIG and services are only available from December 1999.

Source. Authors' calculations. 
Table 3. Estimates of inflation persistence in the euro area, UK and Italy

\begin{tabular}{|c|c|c|c|c|c|c|}
\hline & \multicolumn{2}{|c|}{ Euro area $^{1}$} & \multicolumn{2}{|c|}{ UK } & \multicolumn{2}{|c|}{ Italy } \\
\hline & $\begin{array}{l}1997- \\
2012 \\
\end{array}$ & $\begin{array}{l}1997- \\
2019 \\
\end{array}$ & $\begin{array}{l}1997- \\
2012 \\
\end{array}$ & $\begin{array}{l}1997- \\
2019 \\
\end{array}$ & $\begin{array}{l}1997- \\
2012 \\
\end{array}$ & $\begin{array}{r}1997- \\
2019 \\
\end{array}$ \\
\hline Overall HICP & 0.61 & 0.84 & 0.91 & 0.87 & 0.59 & 0.86 \\
\hline Food \& non-alcoholic beverages & 0.76 & 0.69 & 0.81 & 0.85 & 0.83 & 0.73 \\
\hline Alcoholic beverages, tobacco \& narcotics & 0.88 & 0.89 & 0.98 & 0.88 & 0.80 & 0.82 \\
\hline Clothing \& footwear & 0.47 & 0.41 & 0.80 & 0.92 & 0.69 & 0.62 \\
\hline Housing, water, electricity, gas \& other fuels & 0.72 & 0.84 & 0.76 & 0.78 & 0.76 & 0.77 \\
\hline Furnishings, household equip. \& routine maintenance & 0.83 & 0.92 & 1.00 & 0.90 & 0.68 & 0.94 \\
\hline Health & 0.78 & 0.81 & 0.58 & 0.67 & 0.71 & 0.75 \\
\hline Transport & 0.46 & 0.73 & 0.70 & 0.75 & 0.66 & 0.77 \\
\hline Communications & 0.82 & 0.84 & 0.88 & 0.89 & 0.85 & 0.73 \\
\hline Recreation \& culture & 0.71 & 0.61 & 0.87 & 0.89 & 0.85 & 0.82 \\
\hline Education & 0.63 & 0.78 & 0.83 & 0.81 & 0.65 & 0.79 \\
\hline Restaurants \& hotels & 0.92 & 0.92 & 0.72 & 0.81 & 0.94 & 0.95 \\
\hline Miscellaneous goods \& services & 0.92 & 0.93 & 0.68 & 0.87 & 0.74 & 0.91 \\
\hline Energy & 0.54 & 0.77 & 0.73 & 0.77 & 0.73 & 0.79 \\
\hline Unprocessed food & 0.59 & 0.49 & 0.67 & 0.74 & 0.79 & 0.56 \\
\hline Processed food & 0.81 & 0.84 & 0.88 & 0.88 & 0.78 & 0.86 \\
\hline Industrial goods excluding energy (NEIG) & 0.59 & 0.74 & 0.94 & 0.94 & 0.61 & 0.90 \\
\hline Services & 0.85 & 0.90 & 0.44 & 0.85 & 0.85 & 0.94 \\
\hline Services - Communication & 0.82 & 0.85 & 0.88 & 0.89 & 0.85 & 0.73 \\
\hline Services - Housing & 0.96 & 0.98 & 0.84 & 0.93 & 0.83 & 0.93 \\
\hline Services - Recreation & 0.81 & 0.81 & 0.79 & 0.86 & 0.93 & 0.95 \\
\hline Services - Transport & 0.83 & 0.88 & 0.53 & 0.70 & 0.57 & 0.81 \\
\hline Services - Miscellaneous & 0.86 & 0.93 & 0.86 & 0.86 & 0.75 & 0.82 \\
\hline
\end{tabular}

Note. ${ }^{1}$ For the euro area, miscellaneous services are unavailable before 1999. NEIG and services are unavailable before 2001.

Source: Authors' calculations.

\section{Discussion}

The empirical analysis has illustrated that Malta shares a number of similarities in terms of inflation persistence with other European countries but it also differs in other important dimensions. In terms of similarities, Malta has registered an increase in its estimate of persistence in the overall HICP inflation after 2012 just like most of the economies considered in this study. Like other countries, part of this increase in persistence was due to energy prices, reflecting both the decline in international oil prices as well as country-specific features, such as hedging agreements intended to stabilize utility prices. However, the degree of inflation persistence in Malta remains lower compared to the other considered. Table 4 shows that for the pre- 2012 period, $83 \%$ of the 23 inflation persistence parameters for Malta were estimated in the range $\rho \leq 0.75$ and $17 \%$ within the range $0.75<$ $\rho<0.90$. No estimate had a persistence parameter higher than 0.90 . On the contrary, around $40 \%-41 \%$ of parameter estimates for the other countries lie in the category $\rho \leq 0.75,46 \%-47 \%$ within $0.75<\rho<0.90$, and $13 \%$ in the range $\rho \leq 0.90$. Extending this exercise to the full sample indicates a drop in persistence estimates in the range $\rho \leq 0.75$ and a corresponding increase in the ranges $0.75<\rho<0.90$ and $\rho \leq 0.90$. Even for the full sample, however, $70 \%$ of all persistence estimates for Malta lie in the $\rho \leq 0.75$ category and no estimate has a persistence higher than 0.90 .

Table 4. Ranges of persistence estimates

\begin{tabular}{lcccccc}
\hline & \multicolumn{3}{c}{$1997-2012$} & \multicolumn{2}{c}{$1997-2019$} \\
\cline { 2 - 6 } & Malta & Small open economies & \\
\cline { 2 - 6 } & $83 \%$ & Larger economies $^{2}$ & Malta & Small open economies $^{1}$ & Larger economies $^{2}$ \\
$0.75<\rho<0.90$ & $17 \%$ & $40 \%$ & $41 \%$ & $70 \%$ & $29 \%$ & $22 \%$ \\
$\rho \geq 0.90$ & $0 \%$ & $47 \%$ & $46 \%$ & $30 \%$ & $54 \%$ & $57 \%$ \\
\hline
\end{tabular}

Note. ${ }^{1}$ Consists of Luxembourg, Cyprus, Estonia, Slovenia and Ireland; ${ }^{2}$ Consists of euro area, UK and Italy.

Source: Authors' calculations. 
A potential limitation of this exercise is the assumption of a relatively constant long-run inflation rate over time. In other words, inflation is assumed not have a unit root. This assumption is clearly satisifed for Malta, which is the focus on this study, as its inflation rate has fluctuated around a fairly constant long-run average since the mid-1990s. This situation applies to most other countries in this study though not all. For instance, the average inflation rate in Estonia and Slovenia exceeded 5\% in their pre-EU membership period, compared to 3.4\% and $2.0 \%$, respectively, in their post-EU membership period (2004-2019). A gradual disinflation process also took place, albeit to a lesser extent, in Ireland. For these countries, the relatively high persistence parameters could be due to this process of disinflation over time, thus potentially leading to artificially high persistence parameters. For these countries, the analysis should be extended to account for changing inflation means or structural breaks, though this is beyond the scope of this study.

\section{Conclusion}

The aim of this paper has been to estimate the degree of inflation persistence of Malta, both for aggregate and disaggregate sub-indices, assess whether it changes after 2012 and compare it to a number of countries in the EU. In terms of the original research questions, the main findings are the following. First, estimates of inflation persistence in Malta are lower than those found in other EU countries. Estimates of persistence in Malta have increased when the sample covers the post-2012 period. In terms of the main sub-components, energy inflation has a substantially higher persistence compared to the pre-2012 period, reflecting the drop in oil prices in euro terms, the impact of the energy reforms introduced since 2013 and hedging agreements aimed at providing stability in energy prices. Persistence in other sub-components remained broadly unchanged, with services tending to exhibit the highest degree of persistence. Most other EU countries have also reported an increase in persistence when the post-2012 period is included in the sample though the estimates for Malta, both at the aggregate and disaggregated indices remain less persistent.

Existing macro-econometric models may be enhanced by researchers following an improved understanding of the underlying determinants and processes for inflation in Malta, both at the aggregate and sectoral level. This could eventually lead to improved tools for simulation analysis as well as forecasting.

Going forward, an interesting avenue for further research would be to complement the intrinsic estimates of persistence with those for expectations and extrinsic sources. This would require utilizing data on survey-based expectations for future inflation as well as looking at cost considerations in the price formation process. In this regard, a more detailed analysis on domestic firms' cost structures and the relationship with price setting behaviours constitutes an intriguing area for further research.

\section{References}

Alogoskoufis, G. S., \& Smith, R. (1991). The Phillips curve, the persistence of inflation, and the Lucas critique: Evidence from exchange-rate regimes. The American Economic Review, 1254-1275.

Altissimo, F., Ehrmann, M., \& Smets, F. (2006). Inflation persistence and price setting behaviour in the Euro area: A summary of the IPN evidence. Occasional Paper No. 46, European Central Bank. https://doi.org/10.2139/ssrn.1688962

Bems, M. R., Caselli, F. G., Grigoli, F., Gruss, B., \& Lian, W. (2018). Expectations' Anchoring and Inflation Persistence. International Monetary Fund. https://doi.org/10.5089/9781484388846.001

Benati, L. (2004). International Evidence on the Inflation Persistence. Paper presented at the NBER summer institute 2004.

Benati, L. (2008). Investigating inflation persistence across monetary regimes. The Quarterly Journal of Economics, 123(3), 1005-1060. https://doi.org/10.1162/qjec.2008.123.3.1005

Berg, A., Karam, P., \& Laxton, D. (2006). Practical model-based monetary policy analysis: A how-to guide. WP/06/81, International Monetary Fund. https://doi.org/10.5089/9781451863413.001

Bratsiotis, G. J., Madsen, J., \& Martin, C. (2015). Inflation Targeting and Inflation Persistence. Economic and Political Studies, 3(1), 3-17. https://doi.org/10.1080/20954816.2015.11673835

Buiter, W. H., \& Jewitt, I. (1981). Staggered wage setting with real wage relativities: Variations on a theme of Taylor. The Manchester School, 49(3), 211-228. https://doi.org/10.1111/j.1467-9957.1981.tb00948.x

Calvo, G. A. (1983). Staggered prices in a utility-maximizing framework. Journal of Monetary Economics, 12(3), 383-398. https://doi.org/10.1016/0304-3932(83)90060-0

Central Bank of Malta. (2011). Wage Dynamics Report. Retrieved from 
https://www.centralbankmalta.org/file.aspx?f=31427

Christiano, L. J., Eichenbaum, M., \& Evans, C. L. (2005). Nominal rigidities and the dynamic effects of a shock to monetary policy. Journal of Political Economy, 113(1), 1-45. https://doi.org/10.1086/426038

Ciccarelli, M., \& Osbat, C. (2017). Low inflation in the euro area: causes and consequences. Occasional Paper No. 181, European Central Bank.

Cogley, T., \& Sargent, T.J. (2005). Drifts and volatilities: monetary policies and outcomes in the post WWII US, Review of Economic dynamics 8.2, 262-302. https://doi.org/10.1016/j.red.2004.10.009

Cogley, T., \& Sbordone, A. M. (2008). Trend inflation, indexation, and inflation persistence in the New Keynesian Phillips curve. American Economic Review, 98(5), 2101-26. https://doi.org/10.1257/aer.98.5.2101

Cogley, T., Primiceri, G. E., \& Sargent, T. J. (2010). Inflation-gap persistence in the US. American Economic Journal: Macroeconomics, 2(1), 43-69. https://doi.org/10.1257/mac.2.1.43

d'Agostino, G., Pieroni, L., \& Scarlato, M. (2018). Evaluating the effects of labour market reforms on job flows: The Italian case. Economic Modelling, 68(C), 178-189. https://doi.org/10.1016/j.econmod.2017.07.011

Demarco, A. (2004). A new measure of core inflation in Malta. Central Bank of Malta Quarterly Review, 2004(2).

Dossche, M., \& Everaert, G. (2005). Measuring inflation persistence: A structural time series approach. Working Paper No. 495, European Central Bank. https://doi.org/10.2139/ssrn.1690515

Franta, M., Saxa, B., \& Smidkova, K. (2010). The role of inflation persistence in the inflation process in the New EU Member States. Czech Journal of Economics and Finance, 6. https://doi.org/10.1111/j.1467-9396.2010.00932.x

Fuhrer, J. C., \& Moore, G. (1995). Inflation Persistence. Quarterly Journal of Economics, 109, 127-159. https://doi.org/10.2307/2118513

Fuhrer, J.C. (2010). Inflation persistence, Handbook of monetary economics. Vol. 3. Elsevier, 423-486. https://doi.org/10.1016/b978-0-444-53238-1.00009-0

Gadzinski, G., \& Orlandi, F. (2004). Inflation persistence in the European Union, the Euro area, and the United States. Working Paper No. 414, European Central Bank.

Galí, J., \& Gertler, M. (1999). Inflation dynamics: A structural econometric analysis. Journal of monetary Economics, 44(2), 195-222. https://doi.org/10.1016/s0304-3932(99)00023-9

Geronikolaou, G., Spyromitros, E., \& Tsintzos, P. (2016). Inflation persistence: The path of labor market structural reforms. Economic Modelling, 58(C), 317-322. https://doi.org/10.1016/j.econmod.2016.06.017

Grech, A. G., Micallef, B., Zerafa, S., \& Gauci, T. (2018). The Central Bank of Malta's First Fifty Years: A Solid Foundation for the Future. Central Bank of Malta publication.

Grech, A. G. (2014). An estimate of the possible impact of lower electricity and water tariffs on the Maltese economy. Central Bank of Malta Working Paper WP/01/2014.

Levin, A. T., \& Piger, J. M. (2004). Is inflation persistence intrinsic in industrial economies? Working Paper No. 334, European Central Bank.

Lünnemann, P., \& Mathä, T. Y. (2004). How persistent is disaggregate inflation? An analysis across EU 15 countries and HICP sub-indices. Working Paper No. 415, European Central Bank.

Micallef, B., \& Ellul, R. (2013). Estimating inflation persistence in Malta. Quarterly Review, (2). Central Bank of Malta.

Misztal, P. (2017). The investigation of inflation persistence in Croatia in the period of 2005-2013. Economic Research-Ekonomska Istraživanja, 30(1), 273-289. https://doi.org/10.1080/1331677x.2017.1305788

O'Reilly, G., \& Whelan, K. (2004). Has euro area inflation persistence changed over time? Working Paper No. 335, European Central Bank.

Pivetta, F., \& Reis, R. (2007). The persistence of inflation in the United States, Journal of Economic Dynamics and Control, 31(4), 1326-1358. https://doi.org/10.1016/j.jedc.2006.05.001

Taylor, J. B. (1980). Aggregate Dynamics and Staggered Contracts, Journal of Political Economy, 88(1), 1-23. https://doi.org/10.1086/260845 
Vladova, Z., \& Pachedjiev, S. (2008). Empirical analysis of inflation persistence and price dynamics in Bulgaria. Discussion Paper DP/70/2008, Central Bank of Bulgaria.

\section{Notes}

Note 1. This is further confirmed by estimating persistence parameters for the individual sub-components of the Food and non-alcoholic beverages sub-index (CP01). In this category, the lowest persistence parameters were registered for vegetables (CP0117), fish and seafood (CP0113) and fruits (CP0116), all of which contain a strong seasonal pattern.

Note 2. The prices of the following categories in the services index are considered as administered: Postal services (CP0810); Other services in respect of personal transport equipment (CP0724); Passenger transport by road (CP0732) and Passenger transport by sea and inland waterway (CP0734). In 2012, these four categories had a weight of $7.6 \%$ in the services index and $3.2 \%$ in the overall HICP index.

\section{Copyrights}

Copyright for this article is retained by the author(s), with first publication rights granted to the journal.

This is an open-access article distributed under the terms and conditions of the Creative Commons Attribution license (http://creativecommons.org/licenses/by/4.0/). 